Scientia Agricola

http://dx.doi.org/10.1590/1678-992X-2016-0057

\title{
Crude glycerin in anaerobic co-digestion of dairy cattle manure increases methane production
}

Silvana Simm ${ }^{1}$, Ana Carolina Amorim Orrico ${ }^{1 *}$, Marco Antonio Previdelli Orrico Junior ${ }^{1}$, Natália da Silva Sunada ${ }^{1}$, Alice Watte Schwingel ${ }^{1}$, Mônica Sarolli Silva de Mendonça Costa²

\author{
${ }^{1}$ Federal University of Grande Dourados/FCA, Rod. Dourados- \\ Itahum, km 12, C.P. 533 - 79804-970 - Dourados, MS \\ - Brazil. \\ ${ }^{2}$ State University of West Paraná - Dept. of Agricultural \\ Engineering, R. Universitária, 2069 - 85819-110 - \\ Cascavel, PR - Brazil. \\ *Corresponding author <anacarolamorim@hotmail.com>
}

Edited by Julio Cesar Pascale Palhares
ABSTRACT: Anaerobic digestion of crude glycerin (CG) along with animal waste has been an excellent option for increasing the production of biogas and methane to achieve efficiency in the treatment of both residues. This study aimed to evaluate improvements in specific productions of biogas and methane, reductions in solid and fibrous components in substrates prepared with dairy cattle manure and CG (containing $14 \%$ glycerol). With these residues, experimental substrates were prepared and placed in 25 batch digesters. Initial content of the TS in the influent was $4 \%$ and CG was added in increasing doses $(0,5,10,15$ and $20 \%$ relative to total solids (TS) of the influent). Results were submitted to ANOVA and orthogonal contrasts to assess the effects of linear and quadratic order and thereby estimate the optimal CG doses through the adjusted models. The highest values for specific production of methane $\left(0.19\right.$ and $0.26 \mathrm{~L} \mathrm{~g}^{-1}$ of TS and volatile solids (VS) added, respectively) were reached with the CG inclusions of 6 and $8 \%$, respectively. Total production of biogas with the inclusion of $6 \% \mathrm{CG}$ was $11 \%$ higher when compared to the control treatment. The largest reduction in VS (48\%) was achieved with the addition of $4 \%$ CG. Addition of CG at levels between 3 and $8 \%$ improved the efficiency of the process of anaerobic digestion with dairy cattle manure. Keywords: glycerol, biogas, anaerobic digestion, solids
Received February 13, 2016

Accepted June 27, 2016 employed, reaching potentials of $421.05 \mathrm{~L} \mathrm{~kg}^{-1}$ volatile solids (VS) added and $83 \%$ methane in batch biodigesters. Athanasoulia et al. (2014) carried out co-digestion of sewage sludge with increasing additions of glycerin and found increases in biogas production immediately after the inclusion. However, biodigester stabilization was not reached, i.e., $\mathrm{pH}$ and biogas production soon dropped. Initial increases in biogas production were credited to the better use of soluble organic material in the substrates when glycerol was added, which produced volatile fatty acids in high concentrations and compromised methanogenic activity.

Anaerobic co-digestion was used in this study with the aim of assessing the increase in specific productions of biogas and methane and enhanced reduction of solid and fibrous constituents by adding crude glycerin to substrates prepared with dairy cattle waste.

\section{Materials and Methods}

(ANP, 2014) - is, therefore, cause for concern. Use of this residue is compromised by its low quality, high moisture content, excessive lipids, and high concentrations of sodium and other elements. Nonetheless, in recycling processes, the glycerol provided to the digestive medium may contribute to improving the process as long as the concentrations of the other constituents, or of the glycerol itself, do not outnumber those microorganisms able to deal with them.

Benefits of the co-digestion of sheep waste with increasing doses of crude glycerin containing $39 \%$ glycerol were verified by a study carried out by Orrico and Orrico (2015). Biogas yield increased with the inclusion of up to $15 \%$ glycerin, which was the maximum level 
The crude glycerin was donated by a biodiesel plant located in Dourados, which uses soybean oil as the main raw material. The glycerin consisted of $95 \%$ TS, with a composition as follows: $14 \%$ glycerol, $78 \%$ lipids and $6 \%$ methanol, and COD (chemical oxygen demand) equal to $1532 \mathrm{~g}$ of $\mathrm{O}_{2} \mathrm{~L}^{-1}$ glycerin.

Dairy cattle manure was collected by scraping the stalls' floors during the animals' confinement period for milking. The manure pile was homogenized after collection and presented $19 \%$ of TS of which $83 \%$ were volatile (VS), and $57 \%$ neutral detergent fiber (NDF). COD was equal to $592 \mathrm{~g}$ of $\mathrm{O}_{2} \mathrm{~kg}^{-1}$ of manure and the most probable number of total and fecal coliforms was $3.48 \times 10^{8}$ per $100 \mathrm{~g}$ of manure.

Before the preparation of the input substrate, an inoculum was prepared and considered ready when reached and kept a constant maximum concentration of methane $(83 \%)$. In the influent of all treatments, the inoculum represented $13 \%$ of TS. At the time of loading the digesters, the inoculum consisted of $1 \% \mathrm{TS}$, with $67 \%$ volatiles, and COD equal to $293 \mathrm{~g}$ of $\mathrm{O}_{2} \mathrm{~L}^{-1}$, but coliforms were not detected.

Substrates composed of dairy cattle manure, glycerin, inoculum and water for dilution were prepared so that all treatments had TS content of $4 \%$. The digesters remained 176 days at room temperature, protected from sunlight and rain throughout the experimental period.

Digesters were built basically with two straight PVC cylinders with 150- and 100-mm diameters and a container with $65-\mathrm{mm}$ diameter for storage of the material to be fermented with an average 1.3-L capacity of substrate in fermentation in each one. Cylinders with 100- and 150-mm diameter were inserted into each other, so that the space between the outer wall of the inner cylinder and the inner wall of the outer cylinder could hold a volume of water ("water seal"). The cylinder with a $100-\mathrm{mm}$ diameter had one end closed and one opening for the release of biogas and was kept submerged in the water seal to provide anaerobic conditions and store the gas produced (represented by Sunada et al., 2014).

The daily volume of biogas produced was determined by measuring the vertical displacement of gasometers according to their cross-sectional area. Gas volume was corrected according to standard conditions for temperature and pressure.

Biogas composition was evaluated weekly to determine the volume of methane produced. Analysis of the biogas composition was perfomed using a Finnigan GC-2001 gas chromatograph equipped with a Porapack $Q$ and molecular sieve column, and thermal conductivity detector in GA-21Plus gas analyzer. Specific productions of biogas and methane were calculated to determine the volume (liters) and the amounts (kg) of TS and VS added in the digesters.

Analyses of TS, VS and hydrogenic potential $(\mathrm{pH})$ were carried out at the beginning and the end of the process (influent and effluent) according to the methodology described by APHA (2012). The NDF and hemicellulose contents were measured in accordance with the methodology proposed by Mertens (2002).

Results generated in the test of anaerobic codigestion were analyzed by ANOVA and orthogonal contrasts were used to evaluate the effects of linear, quadratic and cubic order. These analyses were performed using the $\mathrm{R}$ statistical computer package (version 3.1.0 for Windows).

\section{Results and Discussion}

The mean values used to estimate the behavior of the parameters assessed and to obtain predictive models are presented in Table 1 . As shown in Figure 1, there was a quadratic effect $(p<0.05)$ according to the prediction models estimated for reductions of TS and VS during the co-digestion of substrates prepared with dairy cattle manure and increasing levels of crude glycerin.

The maximum reduction (37\%) of TS was reached at the level of $5 \%$ glycerin, while the best reduction of VS (48\%) occurred at the optimum inclusion dose of $4 \%$ glycerin in the TS of the influent. Although TS and VS reductions were improved by the inclusion of glycerin in the substrates, increases in these degradations were only 3 and $1 \%$, respectively, when compared to substrates without added glycerin. Reductions in organic material in digestion are essential to reducing the polluting capacity of the waste, and they also represent the potential for

Table 1 - Mean reduction of the solid and fibrous constituents, of specific biogas and methane productions, of the proportion of methane in biogas, and $\mathrm{pH}$ values during anaerobic co-digestion of crude glycerin with dairy cattle waste in batch biodigesters.

\begin{tabular}{|c|c|c|c|c|c|c|c|c|c|c|c|}
\hline \multirow{3}{*}{ Doses } & \multirow{2}{*}{\multicolumn{4}{|c|}{ Reductions (\%) }} & \multicolumn{4}{|c|}{ Productions $\left(\mathrm{L} \mathrm{g}^{-1}\right)$ Biogas } & \multirow{3}{*}{ Methane (\%) } & \multirow{2}{*}{\multicolumn{2}{|c|}{$\mathrm{pH}$}} \\
\hline & & & & & \multicolumn{2}{|c|}{ Biogas } & \multicolumn{2}{|c|}{ Methane } & & & \\
\hline & TS & VS & Hem & Cel & TS ad & VS ad & TS ad & VS ad & & Ini & Fin \\
\hline 0 & 35.6 & 47.3 & 19.7 & 35.8 & 0.25 & 0.35 & 0.17 & 0.24 & 68.1 & 7.8 & 7.7 \\
\hline 5 & 37.8 & 48.4 & 22.8 & 35.0 & 0.27 & 0.36 & 0.20 & 0.27 & 74.0 & 8.0 & 7.8 \\
\hline 10 & 35.3 & 46.1 & 24.5 & 34.7 & 0.26 & 0.35 & 0.19 & 0.26 & 73.0 & 8.0 & 7.7 \\
\hline 15 & 33.1 & 42.9 & 26.8 & 35.2 & 0.22 & 0.30 & 0.16 & 0.21 & 71.0 & 8.0 & 7.6 \\
\hline CV (\%) & 1.2 & 1.3 & 2.6 & 2.0 & 1.1 & 2.0 & 1.9 & 1.6 & 1.8 & 0.6 & 1.0 \\
\hline
\end{tabular}

$\mathrm{TS}=$ total solids; VS = volatile solids; Hem = hemicelluloses; Cel = cellulose; Ini $=$ initial; Fin = final; CV = coefficient of variation. 
biogas and methane production. However, the amounts reduced during the process are dependent on the composition of the substrates.

Glycerin used in this study contained high levels of lipid (78\%) and the increase of organic load in digestion caused by the inclusion of this fraction in substrates may have compromised the solids reductions. Gigestion of lipids in an anaerobic medium improves the yields of methane and biogas production, in addition to providing greater degradability of the mixtures in digestion. But, concentrations higher than $670 \mathrm{~g}$ of COD per liter of influent may cause accumulation of long chain fatty acids and also volatile fatty acids, lowering the $\mathrm{pH}$ and directly impairing methanogenic activity (Cirne et al., 2007). According to the experimental conditions of this study, the substrates prepared with $0,5,10,15$ and $20 \%$ glycerin resulted in COD of 453.0, 838.0, 1202.1, 1587.2 and $1856.9 \mathrm{~g}$ of $\mathrm{O}_{2}$ per liter, which represent a range of values that may have limited the conditions of digestion.

Superior results of solids reduction were reported by Orrico Junior et al. (2010) when evaluating manure of cattle fed diets with different ratios of forage-concentrate in batch digesters with hydraulic retention time (HRT) of 120 days. Reductions of $46 \%$ of TS and $62 \%$ of VS were obtained from manure generated with $60 \%$ forage, while with $40 \%$ forage the reduction of TS was $61 \%$ and VS $63 \%$. These high values reached by the authors can be attributed to the quality of diets, especially forage, since fibrous constituents are a limiting factor in the degradation of substrates and the presence of glycerin may have changed the conditions of the medium in digestion.

Based on biogas yield at 70 days of retention time during the experimental period, the treatment without added glycerin had already produced $95 \%$ of the total volume of biogas and the substrates with inclusion of 5 , 10,15 and $20 \%$ glycerin had produced 91, 82, 41 and 36 $\%$ of the total volume of biogas, respectively. Therefore, the organic matter degraded in less time and for this reason, the experiment could have been finished earlier

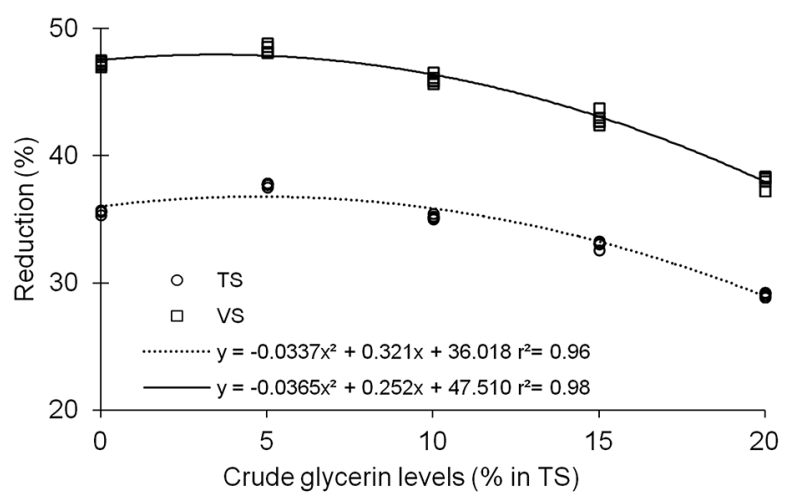

Figure 1 - Reductions of TS (total solids) and VS (volatile solids) in substrates prepared with dairy cattle manure and increasing levels of crude glycerin in batch digesters. for the treatments with 0,5 and $10 \%$ glycerin, since at 112 days the three treatments reached $100 \%$ of biogas production. However, according to the concentrations of methane in the biogas (Figure 2), the dose of $6 \%$ glycerin promoted the highest volumetric yield of methane $(11 \mathrm{~L})$, which was $11 \%$ superior to the treatment without crude glycerin. The highest methane concentrations were achieved firstly in the treatments with glycerin, demonstrating that, despite the degradations of the solids in digestion having taken longer, substrates containing glycerin sped up the production of methane. One of the most important parameters in biogas production is the increase of methane concentration with the addition of glycerin. This is an expected and desirable outcome because the fuel gas is a major indicative of efficiency in the waste digestion (Orrico and Orrico, 2015).

Reductions in the fibrous constituents (cellulose and hemicellulose, Figure 3) indicated that the greatest degradations of cellulose occurred according to the addition of glycerin in the composition of the substrates in digestion, but they were lower than hemicellulose, prob-

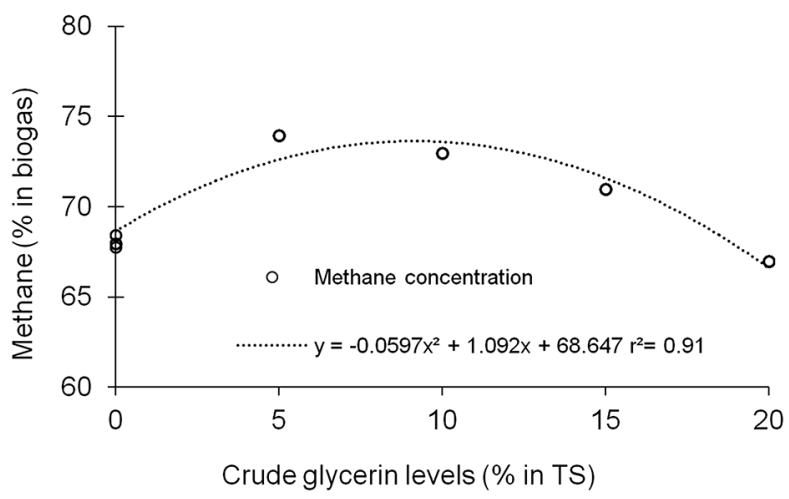

Figure 2- Concentrations of methane in the biogas produced from anaerobic co-digestion of dairy cattle manure and crude glycerin in batch digesters. TS $=$ total solids

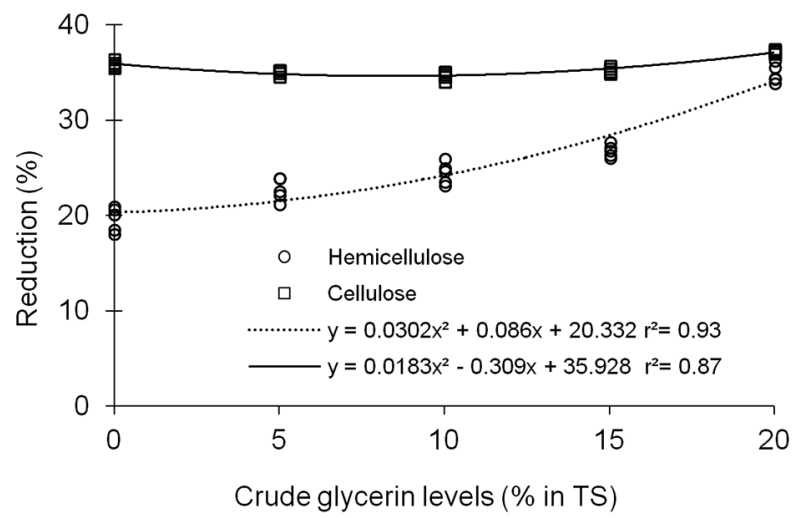

Figure 3 - Reductions of cellulose and hemicellulose in substrates prepared with dairy cattle manure and increasing levels of crude glycerin in batch digesters. TS $=$ total solids. 
ably because cellulose is associated with lignin, which makes it a constituent of hard degradation. There was a quadratic effect on hemicellulose reduction when the highest reduction (35\%) reached the maximum dose of glycerin $(20 \%)$. There was also high statistical correlation $(p<0.01)$ between the reductions of hemicellulose and final $\mathrm{pH}$ values (Figure 4), indicating that the acidification of the medium promoted by the addition of glycerin to the composition of the substrates affected the reductions due to the hemicellulose solubilization in an acid medium.

The acidification of the medium according to the increase in glycerin doses is due to microbial metabolism in the digesters. In substrates that contain carbohydrates of rapid degradation, a rapid increase in the population of bacteria also occurs. It is responsible for the processes of hydrolysis and acidogenesis and the doubling time of these microorganisms is on average 2-3 h (Shida et al., 2009). In addition to $14 \%$ glycerol, glycerin had large amounts of lipids (78 \%). Lipids also quickly degrade into organic acids (such as propionic and butyric) that are oxidized into acetate and subsequently generate methane. The drop in $\mathrm{pH}$ occurs because the archaea responsible for assimilation of the acids have a much slower doubling time of 1 to 9 days (Jetten et al., 1992), generating an acid accumulation in the medium.

According to the results of specific productions of biogas per added solids (Figure 5A), the dose of $6 \%$ crude glycerin promoted the highest yield of biogas per TS $\left(0.267 \mathrm{~L} \mathrm{~g}^{-1}\right)$, while the addition of $4 \%$ glycerin generated the maximum yield of biogas per VS $\left(0.364 \mathrm{~g} \mathrm{~L}^{-1}\right)$. For the specific production of methane (Figure 5B), the maximum yields of 0.196 and $0.264 \mathrm{~L}$ of methane per gram of TS and VS added were reached with the optimal doses of glycerin inclusion of 8 and $6 \%$ (in relation to the substrate TS), respectively. These values represented increases of 13 and $10 \%$ when compared with the results of the treatment without the addition of glycerin.

When using cattle manure fed only roughage, Alvarez et al. (2006) obtained inferior results of specific

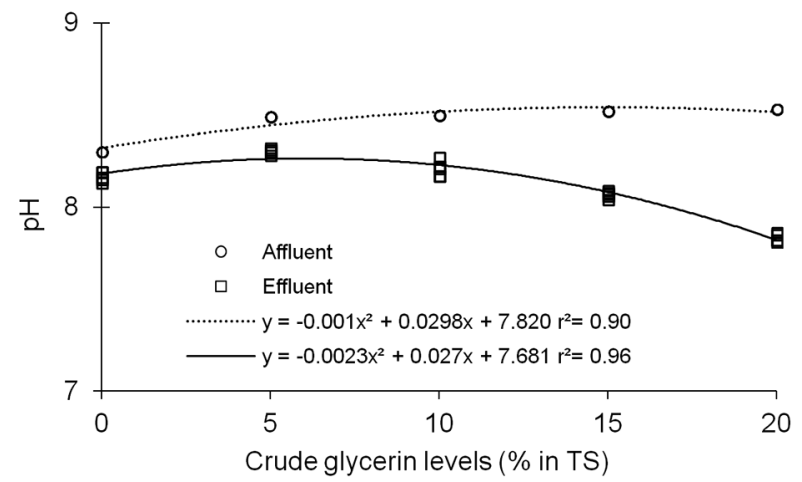

Figure $4-\mathrm{pH}$ behavior of the influent and effluent for evaluation of anaerobic co-digestion of crude glycerin with dairy cattle manure in batch digesters. TS $=$ total solids. production of methane of $0.131 \mathrm{~L} \mathrm{~g}^{-1}$ VS added, which is probably related to the shorter time that the material remained in digestion (HRT of 50 days) and the differences in animal diets, since without the inclusion of crude glycerin, the authors achieved a production of $0.239 \mathrm{~L} \mathrm{~g} \mathrm{~g}^{-1}$ VS added. In contrast, Moller et al. (2004) using cattle manure fed $55 \%$ roughage obtained better results (0.207 $\mathrm{L} \mathrm{g}^{-1} \mathrm{VS}$ ) than Alvarez et al. (2006), but still lower than the current study, which may also be attributed to the composition of the residue and the beneficial effect of glycerin inclusion.

Crude glycerin inclusion greater than $6 \%$ caused a decline in specific production of methane per VS added, which is probably indicative of overload of organic material in the medium in digestion. This outcome may be associated with the poor quality of the crude glycerin due to a high content of lipid. As stated by Long et al. (2012), lipids can have a negative effect on methanogenic archaea in high concentrations or loading rates, because they are composed of triglycerides and long chain fatty acids.

The rapid degradation of substrates in digesters results in a greater release of acids in the medium, which consequently inhibits methane production (Astals et al., 2011), possibly in virtue of the elevated sensitivity of methanogenic microorganisms to the changes in the medium and their slower growth rate (Jetten et al., 1992).
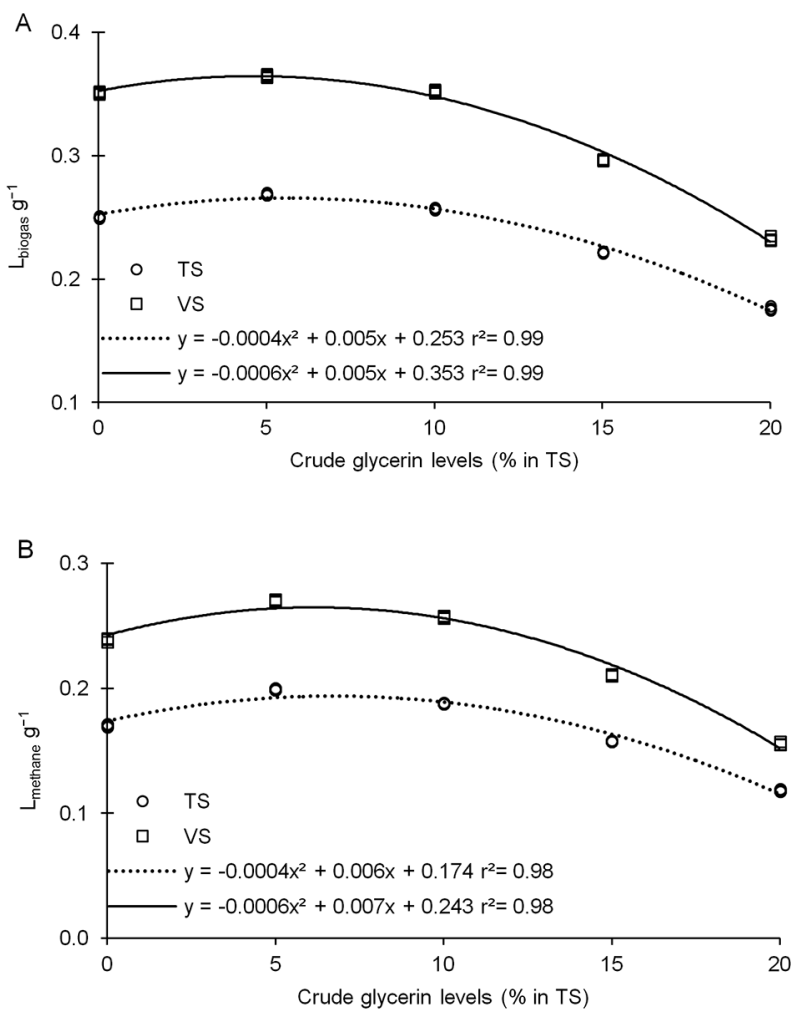

Figure 5 - Behaviors and predicting models of the effect of glycerin levels on the specific productions of biogas (A) and methane (B) per total solids (TS) and volatile solids (VS) added. 
According to Jensen et al. (2014), the inclusion of glycerol in co-digestion has numerous advantages relating to its biodegradability, which improves the efficiency of this process. However, the amount added to the system must be taken into account, since it increases the organic load and may lead to overload and failure of the process. The aforementioned authors reported an optimal dose of $2 \%$ glycerol in relation to the volume of digesters during co-digestion of sewage sludge, resulting in a $50 \%$ increase in methane production. In addition, glycerol inclusions above this value became limiting even under ideal conditions of temperature and agitation. Thus, the recommendation made by these authors was based on the inclusion of high purity glycerin (98\% glycerol), which can be somewhat impractical for the preparation of substrates in Brazil, since the glycerin generated in the country may contain reduced glycerol content, as occurred in this study. Even when crude glycerin with low glycerol content was used, a positive effect was found for inclusions at 3 and $8 \%$ in co-digestion with dairy cattle waste. At this inclusion level, the maximum reductions in TS and VS (37 and 48 $\%$, respectively) and the highest specific productions of biogas and methane (reaching 0.364 and $0.294 \mathrm{~L}$ biogas and methane, respectively, per gram of VS added) were found. It is clear that these results are beneficial to the environment and can also improve the profitability of production units with power generation from renewable sources and production of organic fertilizers in terms of quality of pasture and forage.

\section{Acknowledgments}

This study was carried out with the financial support of the Federal University of Grande Dourados (UFGD) and the Foundation for the Development of Education, Science and Technology in the state of Mato Grosso do Sul (Fundect). In addition, the authors would like to thank the Coordination for the Improvement of Higher Level Personnel (CAPES) for granting the Master degree scholarship.

\section{References}

Agência Nacional do Petróleo [ANP]. 2014. Brazilian statistical yearbook of petroleum, natural gas and biofuels = Anuário estatístico Brasileiro do petróleo, gás natural e biocombustíveis. Available at: http://www.anp.gov.br [Accessed Jan 16, 2016] (in Portuguese).

Alvarez, R.; Villca, S.; Lidén, G. 2006. Biogas production from llama and cow manure at high altitude. Biomass and Bioenergy 30: 66-75.

American Public Health Association [APHA]. 2012. Standard Methods for the Examination of Water and Wastewater. 22ed. American Public Health Association, Washington, DC, USA.

Astals, S.; Ariso, M.; Galí, A.; Mata-Alvarez, J. 2011. Co-digestion of pig manure and glycerin: experimental and modelling study. Journal of Environmental Management 92: 1091-1096.
Athanasoulia, E.; Melidis, P.; Aivasidis, A. 2014. Co-digestion of sewage sludge and crude glycerol from biodiesel production. Renewable Energy 62:73-77.

Cirne, D.G.; Paloumet, X.; Björnsson, L.; Alves, M.M.; Mattiasson, B. 2007. Anaerobic digestion of lipid-rich waste: effects of lipid concentration. Renewable Energy 32: 965-975.

Instituto Brasileiro de Geografia e Estatística [IBGE]. 2013. Municipal livestock production $=$ Produção da pecuária municipal. Available at: http://www.ibge.gov.br/home/ estatistica/economia/ppm/2013 [Accessed Dec 08, 2015] (in Portuguese).

Jensen, P.D.; Astals, S.; Lu, Y.; Devadas, M.; Batstone, D.J. 2014. Anaerobic co-digestion of sewage sludge and glycerol, focusing on process kinetics, microbial dynamics and sludge dewaterability. Water Research 67: 355-366.

Jetten, M.S.M.; Stams, A.J.M.; Zehnder, A.J.B. 1992. Methanogenesis from acetate: a comparison of the acetate metabolism in Methanothrix soehngenii and Methanosarcina spp. FEMS Microbiology Letters 88: 181-198.

Long, J.H.; Aziz, T.N.; Los Reyes, F.L.; Ducoste, J.J. 2012. Anaerobic co-digestion of fat, oil and grease (fog): a review of gas production and process limitations. Process Safety and Environmental Protection 90: 231-245.

Mertens, D.R. 2002. Gravimetric determination of amylasetreated neutral detergent fibre in feeds with refluxing beakers or crucibles: collaborative study. Journal of the Association of Official Analytical Chemists 85: 1217-1240.

Moller, H.B.; Sommer, S.G.; Ahring, B.K. 2004. Methane productivity of manure, straw and solid fractions of manure. Biomass Bioenergy 26: 485-495.

Orrico, M.A.P.; Orrico, A.C.A. 2015. Quantification, characterization, and anaerobic digestion of sheep manure: the influence of diet and addition of crude glycerin. Environmental Progress Sustainable Energy 34: 1038-1043.

Orrico Junior, M.A.P.; Orrico, A.C.A.; Lucas Junior, J. 2010. Effects of roughage: concentrate in relation to time of hydraulic retention under anaerobic biodigestion of cattle manure. Engenharia Agrícola 30: 386-394 (in Portuguese, with abstract in English).

Shida, G.M.; Barros, A.R.; Reis, C.M.; Amorim, E.L.C.; Damianovic, M.H.R.Z.; Silva, E.L. 2009. Long-term stability of hydrogen and organic acids production in an anaerobic fluidized-bed reactor using heat treated anaerobic sludge inoculum. International Journal of Hydrogen Energy 34: 36793688.

Sunada, N.S.; Lucas Junior, J.; Orrico, A.C.A.; Orrico Junior, M.A.P.; Schwingel, A.W.; Costa, M.S.S.M. 2014. Addition of lipolytic enzyme in anaerobic co-digestion of swine manure and inclusion levels of waste vegetable oil. International Journal of Agricultural Policy and Research 2: 468-474.

Zhang, C.; Xiao, G.; Peng, L.; Su, H.; Tan, T. 2013. The anaerobic co-digestion of food waste and cattle manure. Bioresource Technology 129: 170-176. 